DEMOGRAPHIC RESEARCH

VOLUME 28, ARTICLE 10, PAGES 271-312

PUBLISHED 13 FEBRUARY 2013

http://www.demographic-research.org/Volumes/Vol28/10/

DOI: $10.4054 /$ DemRes.2013.28.10

Research Article

\title{
Progress in Spatial Demography
}

\section{Stephen A. Matthews}

\section{Daniel M. Parker}

This publication is part of the Special Collection on "Spatial Demography", organized by Guest Editor Stephen A. Matthews.

(C) 2013 Stephen A. Matthews \& Daniel M. Parker.

This open-access work is published under the terms of the Creative Commons Attribution NonCommercial License 2.0 Germany, which permits use, reproduction \& distribution in any medium for non-commercial purposes, provided the original author(s) and source are given credit.

See http:// creativecommons.org/licenses/by-nc/2.0/de/ 


\section{Table of Contents}

$\begin{array}{lll}1 & \text { Introduction } & 272\end{array}$

2 Demography as a "spatial science" 274

$\begin{array}{lll}2.1 & \text { Spatial analysis } & 277\end{array}$

2.2 Spatial econometrics 277

$2.3 \quad$ Geographically Weighted Regression 280

$2.4 \quad$ Multilevel modeling 283

2.5 Spatial Pattern Analysis 286

$3 \quad$ Background to the Special Collection 288

4 Discussion: The near future in spatial demography 292

$5 \quad$ Acknowledgements 295

References $\quad 296$ 


\title{
Progress in Spatial Demography ${ }^{1}$
}

\author{
Stephen A. Matthews ${ }^{2}$
}

Daniel M. Parker ${ }^{3}$

\begin{abstract}
BACKGROUND

Demography is an inherently spatial science, yet the application of spatial data and methods to demographic research has tended to lag that of other disciplines. In recent years, there has been a surge in interest in adding a spatial perspective to demography. This sharp rise in interest has been driven in part by rapid advances in geospatial data, new technologies, and methods of analysis.
\end{abstract}

\section{OBJECTIVES}

We offer a brief introduction to four of the advanced spatial analytic methods: spatial econometrics, geographically weighted regression, multilevel modeling, and spatial pattern analysis. We look at both the methods used and the insights that can be gained by applying a spatial perspective to demographic processes and outcomes. To help illustrate these substantive insights, we introduce six papers that are included in a Special Collection on Spatial Demography. We close with some predictions for the future, as we anticipate that spatial thinking and the use of geospatial data, technology, and analytical methods will change how many demographers address important demographic research questions.

\footnotetext{
${ }^{1}$ This paper is intended as both a stand-alone resource and as an introduction to a special collection in Demographic Research focusing on "advanced methods in spatial demography."

${ }^{2}$ Direct all correspondence to Stephen A. Matthews, Department of Sociology, Population Research Institute, The Pennsylvania State University, 601 Oswald Tower, University Park, PA 16802-6211, USA (E-mail: matthews@psu.edu or sxm27@psu.edu). Associate Professor of Sociology, Anthropology, Demography and Geography, Faculty Director of the Geographic Information Analysis Core, Population Research Institute, Social Science Research Institute, The Pennsylvania State University.

${ }^{3} \mathrm{PhD}$ Candidate, Department of Anthropology and Dual-Degree in Anthropology and Demography, The Pennsylvania State University.
} 


\section{CONCLUSION}

Many important demographic questions can be studied and framed using spatial approaches. This will become even more evident as changes in the volume, source, and form of available demographic data-much of it geocoded-further alter the data landscape, and ultimately the conceptual models and analytical methods used by demographers. This overview provides a brief introduction to a rapidly changing field.

\section{Introduction}

Demographic research involves the study of complex patterns of interrelated social, behavioral, economic, and environmental phenomena. Thus, scholars have increasingly argued that spatial thinking and spatial analytical perspectives have important roles to play in uncovering answers to demographic questions (Voss 2007a; Logan, Zhang, and $\mathrm{Xu}$ 2010). Spatial demography is concerned with the spatial analysis of demographic processes and outcomes, and has typically drawn on macro-level or ecological data. A new journal, Spatial Demography, has defined spatial demography as the "spatial analysis of demographic processes." In recent years, the revival in spatial demography (Voss 2007a) has been supplemented by the integration of micro- and macrodemography, and the linking of data on people to data on places (Entwisle 2007). This integration has led many demographers to express an interest in harnessing geospatial technologies to collect, manage, and analyze new forms of geospatial data that could prove helpful in addressing research and policy questions. Demographic research depends on the collection and analysis of individual- and contextual-level data across a wide range of spatial and temporal scales. Indeed, this is evident in demographic research on issues such as racial/ethnic segregation and other forms of social stratification and inequality, health behaviors, morbidity and mortality, fertility, family structure/transitions and aging, and population-environment interactions (Entwisle 2007). As we acquire more fine-tuned and linked spatial and temporal data, the ability to understand migration and mobility will be enhanced. Entwisle (2011) highlighted several new areas for exploration, including the following: life-course transitions and spatial mobility, social and spatial mobility, neighborhoods and migration, social

\footnotetext{
${ }^{4}$ The new journal will be launched in early 2013: See: http://spatialdemography.org/. Voss (2007, p. 458) defines spatial demography as "the formal demographic study of areal aggregates, i.e., of demographic attributes aggregated to some level within a geographic hierarchy." Voss's article briefly discusses other definitions of spatial demography.
} 
networks and migration, tourism and ecological impacts, and the distributional and mobility implications of climate change. ${ }^{5}$

Researchers from many different social science fields have already added spatial analysis to their methodological arsenals, having realized that the spatial perspective can serve as a potential incubator for innovative social science and interdisciplinary research (Goodchild et al. 2000; Goodchild and Janelle 2004; 2010; Janelle and Goodchild 2011; Butz and Torrey 2006). While interest in spatial demography has been evident throughout the history of the core discipline of demography, the degrees to which spatial thinking and different forms of spatial analysis have been utilized have been very uneven (Weeks 2004; Voss 2007a; Castro 2007). In the 1990s-a boom period for GIS and spatial analysis across many social sciences-very few empirical publications in demographic research embraced the emerging forms of geospatial data or incorporated spatial thinking and modeling. ${ }^{6}$ There were several notable exceptions, such as Anderton et al. (1994) and Entwisle et al. (1996); and there were several specialized edited books, particularly in the area of population and environment research (see Liverman et al. 1998).

The most recent surge in interest in adding a spatial perspective in the population sciences has been driven by the ready availability of geospatial data and the refinement and emergence of GIScience tools to analyze them, including geographic information systems (GIS), spatial analysis, and spatial statistics (de Smith et al. 2007; Matthews 2011a). This paper has three main sections. First, we provide an introduction to the recent re-emergence of spatial demography that includes a general overview of some of the advanced spatial analytic methods now available to demographers: specifically, spatial econometrics, geographically weighted regression, multilevel modeling, and spatial pattern analysis. While our emphasis is on methodology, in the overview we stress the importance of the insights gained by applying a spatial perspective to demographic processes and outcomes. Our goal is not to provide a comprehensive overview, but rather to offer examples from a diverse selection of demographic research

\footnotetext{
${ }^{5}$ Entwisle's comments were part of a presentation at the Future Directions in Spatial Demography Specialist Meeting (Santa Barbara, CA) in December 2011. This presentation and others, plus more than 40 short position papers, are available at http://ncgia.ucsb.edu/projects/spatial-demography.

${ }^{6}$ Consider a comparison between demography and the adoption of spatial analysis in the fields of public health and epidemiology. In the latter, spatial analysis grew rapidly during the late-1990s, spurred on in part by the emergence of new forms of data, geospatial data warehouses, and specialized journals, such as the International Journal of Health Geographics (Cromley and McLafferty 2011). Two areas of public health significance that have seen particularly rapid growth in the use of GIS, innovative geospatial databases, and advanced spatial analysis include two dimensions of the obesity epidemic: physical activity (PA) research and studies of food environments. In examples of early work in these areas, geospatial data were used to create objective measures of the physical environment, such as walkability (Saelens et al. 2003) and built retail environments, or the density of fast food outlets and/or grocery stores (Morland et al. 2002; Austin et al. 2005; and Zenk et al. 2005). The field of obesity research and GIS has grown rapidly in the past five years (Matthews 2012).
} 
areas. In the second part of our paper, we provide some brief background information on the Demographic Research Special Collection on "Spatial Demography," as well as a description of each of the accompanying papers, including a summary of each paper's substantive findings. In the final section of this paper, we offer some predictions for the future, as we anticipate that new forms of spatial data and new methods (and method integration) will be used to address many of the most important demographic research questions of the early $21^{\text {st }}$ century.

\section{Demography as a "spatial science"}

Menken, Blanc, and Lloyd (2002), in a review of training and support for population scientists, stated that "the broadening of the field has also necessitated the acquisition of additional skills and familiarity with the concepts and tools of related disciplines." Spatial analysis is one such area, as demographers may benefit from acquiring spatial analysis skills and understanding spatial concepts. But this is easier said than done. The improved application of geospatial data and spatial methods to demographic research has been repeatedly identified as a critical methodological challenge facing demographers (NICHD 2002). ${ }^{7}$ Five to 10 years ago, the availability of graduate-level training in GIS in general, and of specific courses in advanced spatial data analysis with significant social science or demographic content, was limited. The current situation (as of 2012) is not much better, and the dearth of spatial analysis training at all educational levels (pre-university, undergraduate, and postgraduate) dominated the discussion at a recent specialist meeting of almost 50 demographers and geographers on the Future of Spatial Demography (see Matthews, Janelle, and Goodchild 2012).

While the provision of GIS and spatial analysis courses is one dimension of training, the inclusion of spatial thinking and analytical methods in demography textbooks is also essential. Within standard demography textbooks, the treatment of spatial analysis is scant to say the least. Indeed, in the most widely known textbooks on demographic techniques and methods, references to spatial analysis are indirect and usually arise as part of a discussion of the geographical hierarchies of census data, or in conjunction with national and sub-national (i.e., regional) attribute data. This is quite a serious instructional gap for a field that is an "inherently spatial science, since it almost always deals with human populations in a defined geographic region" (Weeks 2004, p. 381). John Weeks' own Population is a rare exception among textbooks on demographic methods and techniques, as the ninth edition, which appeared in 2006,

\footnotetext{
${ }^{7}$ The NICHD/DBSB (2002) report also noted that spatial demographic research needed to address issues of theory, improving data accessibility and compatibility with spatial techniques, and fostering interdisciplinary research.
} 
included a few pages devoted to GIS, geospatial data, and spatial analysis (although in later editions this coverage expanded considerably). Namboodiri (1991) included a chapter, entitled "Spatial Distribution," which provided an introduction to spatial methods that could be applied to demography. ${ }^{8}$ In sum, a specialist textbook on "spatial demography" currently does not exist (it should be noted, however, that there are publications on spatial population analysis and developments in spatial demography [Rees and Wilson, 1977; Woods and Rees, 1986], as well as on multiregional demography [Rogers 1975, 1995] and applied population geography (Plane and Rogerson 1994)). The emphasis in these earlier textbooks was on demographic data about places rather than on the utilization of spatially explicit models, which emerged later due to developments in geospatial databases, GIS, spatial analysis, and spatial statistics.

Although demography textbooks on GIS and spatial analysis are scant, the perspective from the GIS/spatial analysis side is little a better. Perhaps the best term to describe the coverage of spatial analysis in the GIS/spatial analysis textbook market is "bifurcated." At one end of the spectrum, there are numerous introductory GIS textbooks and workbooks that increasingly focus on applied social, health, and even demographic issues. However, in these introductory texts the treatment of spatial analysis beyond cartography, spatial querying, overlay, and buffer analysis is either non-existent or minimal. At the other end of the spatial analysis textbook market, there are the advanced spatial statistics texts; Cressie's (1991) classic text on Statistics for Spatial Data immediately comes to mind. More specifically, there are several spatial econometric texts (Anselin 1988; LeSage and Pace 2009), although again these texts barely address demographic research questions. To say that a complete bifurcation has taken place would be an exaggeration, as there are a few high-end/intermediate texts (Bailey and Gatrell 1996; Haining 2003; O'Sullivan and Unwin 2010), primers (Fotheringham, Brunsdon, and Charlton 2002; Bivand, Pebesma, and Gómez-Rubio 2008), handbooks (Anselin and Rey 2010; Fischer and Getis 2010; and, Fotheringham and Rogerson 2009), and focused applications in demography-related fields, such as the book on GIS and Public Health by Cromley and McLafferty (2002; second edition, 2011). This advanced and intermediate literature was picked up by a small set of demographers, and the recent emergence of spatial demography can be traced back to two special journal issues offering a taste of the potential for innovative population research. Both special issues appeared under the general rubric of spatial demography: the special issues of the Proceedings of the National Academy of Sciences (PNAS)

\footnotetext{
${ }^{8}$ Namboodiri's chapter discusses spatial data, spatial probability models and point pattern analysis, spatial autocorrelation, cross-product statistics, spatial regression, and methods for dealing with correlated error terms.
} 
edited by Wachter (2005) and a special issue of Population Research and Policy Review edited by Voss (2007b).

Voss' essay, "Demography as a spatial social science" (Voss 2007) is a useful landmark paper that reminds demographers of our strong spatial heritage. While Voss focused on academic research in the $20^{\text {th }}$ century, the origins of spatial thinking and analysis in demographic research can be traced back to at least the period of la statistique morale in France (1820s and 1830s), and especially to the work of Guerry, D'Angeville, Duplin, and Quetelet (see Robinson 1982). Voss (2007a) predicted an exciting future for quantitative spatial demographers. ${ }^{9}$ The Weeks (2004) paper was equally important, as it provided an overview of how demography can gain from the incorporation of spatial thinking, and of the role spatial analysis can play in the development and testing of demographic theory. ${ }^{10}$ In a similarly important synthesis, Castro (2007) provided detailed reviews of spatial perspectives and model applications structured around demography's core areas-fertility, mortality, migration, and population models - all with a focus on the implications for population policy research. ${ }^{11}$

Many of the early adopters of spatial analysis in demography drew upon specific geospatial data sets, utilized non-census data/units of analysis (as well as census data/units), and adopted fairly rudimentary forms of spatial analysis - from overlay, buffering, and spatial joins (for building contextual databases and descriptive analysis) - but only a relatively small number had adopted more advanced geostatistics and point pattern analysis (e.g., Castro et al. 2006) and spatial regression (e.g., Morenoff 2003; Voss et al. 2006; Chi and Zhu 2008). Increasingly, researchers across the population sciences are developing innovative ways to both harness and analyze geospatial data on the social, built, and physical environment contexts of individual lives.

\footnotetext{
${ }^{9}$ Further evidence of innovative and high-quality spatial demography can be found in Matthews' (2011) annotated bibliography on spatial analysis in the social and demographic sciences, which includes summaries of up to 100 books, articles, and resources that focus mainly on spatial inequality, residential segregation, demography, and crime. Some of these studies are referred to in later sections of this paper. A version of this annotated bibliography is available from the author.

Logan et al. (2010) and Logan (2012) also provide an important - and a more cautious - review of both the challenges and the opportunities that confront spatial demographers and sociologists, respectively (for a review of the challenges and opportunities in social epidemiology and preventive medicine, see Matthews, Moudon, and Daniel 2009).

${ }^{10}$ Weeks' focused on fertility in Egypt, but his chapter was part of an edited collection on spatially integrated social science, a collection that included several papers by leading U.S.-based demographers and sociologists covering the spatial analysis of substantive areas such as neighborhood crime, race/ethnic segregation, migration, fertility decline, and population and environment research.

${ }^{11}$ Both Weeks and Castro provided coverage of international demographic research, unlike Voss, who focused mostly on U.S. research.
} 
While these special issues and related activities are indicative of the rapid growth in interest in spatial demography, much has changed in the past five years. In the following section, we provide a brief overview of the main methodological approaches used in spatial integrated demographic research, and a discussion of how these methods have been applied in some of the most recent publications in our field.

\subsection{Spatial analysis}

A prerequisite for spatial analysis of any form-whether basic or advanced - is the availability of information on locations (i.e., places, variously defined), the attributes of those locations (e.g., poverty rates, educational attainment, or disease prevalence), and the functional and geographic connections between locations (distance, adjacency, or hierarchical structures). The diversity of the spatial analytical methods available to demographic researchers is certainly wide, and it continues to expand; see the recent handbooks by Anselin and Rey (2010), Fischer and Getis (2010), and Fotheringham and Rogerson (2009). These new opportunities for demographers are also a function of the different types of analytical units and emerging data formats used in formal spatial analysis: specifically, point data (e.g., disease cases), line data (e.g., networks, routes), spatial continuous or field data (e.g., accessibility surfaces), and area or lattice data (e.g., mortality rates, poverty).

In our overview, we have chosen to focus on the recent advances in the spatial analysis of social science data in four methodological areas: spatial economics, geographically weighted regression, multilevel or hierarchical models, and spatial pattern analysis. Of these, multilevel modeling, increasingly incorporating Bayesian methods for estimating prior distributions and place effects, has been the most popular and the best known in demography-related journals (Entwisle 2007). However, the other spatial methods are also starting to appear in the demographic literature with more frequency.

\subsection{Spatial econometrics}

Spatial econometrics accounts for spatial effects in regression analyses (Anselin 2010). Ultimately, if geography or place matters (and it frequently does), then things that are more related geographically (i.e., more proximate geographically) are also correlated in other ways. Therefore, assumptions about the independence of covariates and about the independence and distribution of error terms are violated in an Ordinary Least Squares (OLS) regression framework. Spatial effects can be roughly divided into two main 
types: spatial dependence (or spatial autocorrelation) and spatial heterogeneity (Anselin 2010). Furthermore, spatial econometric methods can be split into three main categories: model specification (sometimes informed by specification testing), model estimation, and spatial predictions.

Model specification usually involves the incorporation of spatial weights matrices to account for the influence of neighboring regions on the variable of interest in the region of interest (Anselin 2003). Spatial weights for neighbor effects can be attributed to dependent and independent variables, as well as to error terms. Spatial dependences often are not homogenous across large geographical regions, and some methods (e.g., geographically weighted regression (GWR); see later section) have been increasingly used for modeling the varying strength of covariate effects on dependent variables (Fotheringham 2009). Model estimation has largely depended on various methods of moments and maximum likelihood estimation (MLE), with ever more sophisticated methods emerging as computational power has increased. For a discussion on spatial prediction, see Kelejian and Prucha (2007).

Many of the most recent advances in spatial econometrics are in the formal results relating to the asymptotic attributes of MLE and the generalized method of moments (GMM) estimation (Lee 2003; 2004; 2007). Other advances have recently been made in model specification beyond spatial lag and spatial error models. Some of these advances have included variations of classic models; for example, Kelejian and Prucha (2002) describe a spatial lag model in which all of the observations are neighbors of each other. Still other advances have involved the extension of GMM to a spatial moving average process, including an endogenous spatial lag, for spatially explicit panel data (Fingleton 2008) as well as variance covariance matrix specification (LeSage and Pace 2007). Spatial models for flows, for panels, and for latent variables are growing in use (Elhorst 2003, 2010; Anselin, Le Gallo, and Jayet 2008).

Bayesian methods in spatial regression analysis are also being used more widely (Schabenberger and Gotway 2005). In a recent study, Savitz and Raudenbush compared OLS, an empirical Bayes estimator with the independence assumption, and an empirical Bayes estimator incorporating spatial dependence for modeling neighborhood environments (Savitz and Raudenbush 2009). The Bayesian method that incorporated spatial dependence was found to be superior to the OLS and the non-spatial Bayes method, especially in situations in which the sample sizes are small and the spatial dependence is strong.

Spatial regression approaches are beginning to appear in population-related research (Voss 2007). In a recent paper, Voss et al. (2006) provided a demonstration that should convince demographers and social scientists to examine spatial autocorrelation in their data, and to explicitly correct for spatial externalities on variables that are spatially referenced. The authors applied exploratory spatial data 
analysis (ESDA) and spatial regression analysis to examine inter-county variation in child poverty rates based on an earlier study by Friedman and Lichter (1998). They found that the explicit acknowledgement of spatial effects in an explanatory regression model considerably improved earlier published results, as it shifted "wrong sign" parameters, reduced the residual squared error, and eliminated any substantive residual spatial autocorrelation.

Sampson, Morenoff, and colleagues have all explored and documented the contribution of spatial regression applications in the Project on Human Development in Chicago Neighborhoods (PHDCN) (Sampson, Morenoff, and Earls 1999; Morenoff, Sampson, and Raudenbush 2001; Morenoff 2003). These researchers also used a coupling of multilevel models and variables derived from spatial weights. Their clearly framed analysis helped to introduce spatial externalities to neighborhood research. ${ }^{12}$ For example, in their paper on "spatial externalities," they found that social capital and collective efficacy for children are relational in character and operate at a higher level of analysis than the individual or the local neighborhood (Sampson, Morenoff, and Earls 1999). This team has also utilized ESDA approaches (e.g., the local Moran's I) and spatial regression-including lag and error models, as well as spatial regime models - to look at the spatial dynamics of urban violence (Morenoff, Sampson, and Raudenbush 2001) and birth weight (Morenoff 2003). Their findings indicated that contextual effects on the individual-level outcomes of interest (e.g., birth weight) extend to the social environment beyond the immediate neighborhood.

Substantively, spatial regression methods are currently being used to investigate a wide range of topics in the social and health sciences. For example, recent papers have examined fertility, migration, mortality, health, population growth, and gender biases in education. A recent study by Echávarri and Ezcurra investigated the potential relationship between education and the sex ratio at birth in India (Echávarri and Ezcurra 2010). Previous research into this potential relationship had been inconclusive, and had not incorporated spatial effects. Using a spatial regression model, the authors found an inverse U-shaped curve for the literacy rate and the sex ratio at birth.

Recently, there have been several methodological papers on applications of spatial regression in demography-related areas, including several studies that integrated social and environmental data. Anselin and Le Gallo (2006) reported on the sensitivity of hedonic models of house prices to the spatial interpolation of measures of air quality in

\footnotetext{
${ }^{12}$ It is important to note that around the same time we see several applications of spatial econometric methods in sociology/crime-related studies, with some based on close collaboration between Luc Anselin and sociologists, criminologists, and demographers. For example, in macro-level crime research, Messner et al. (1999) found evidence of strong positive spatial autocorrelation of homicide rates, and that some of the relations between homicide and its covariates are not stable across space. In a related paper, Baller et al. (2001) re-examined the impact of conventional structural covariates on homicide rates, and explicitly modeled spatial effects.
} 
Southern California. They observed a high degree of residual spatial autocorrelation, which warranted the inclusion of a spatially lagged dependent variable in their regression models. In an innovative paper, Pais and Elliott (2008) combined census data and biophysical data on wind speed in models of the spatial variation in hurricane damage and recovery in four regions of the United States during the early 1990s. Other recent applications of spatial econometrics include a study by De Jong et al. (2006) of spatial dependence and diffusion in state welfare policies in the U.S., and an analysis by Yang, Jensen, and Haran (2011). After comparing three different spatial econometrics models (error, lag, and generalized) with OLS models in their study of social capital and mortality, Yang and colleagues concluded that advanced spatial regression methods facilitated a better understanding of the data, and yielded unbiased analytic results and an optimal model fit.

While it appears that the importance of space in regression methods is now widely recognized in the social sciences, the choice of areal unit remains problematic (i.e., modifiable areal unit problem, or MAUP, see Openshaw 1984). However, the next two methods we will discuss, GWR and multilevel modeling, have largely been developed to cope with issues of scale. More specifically, both the GWR and multilevel approaches attempt to link macro-level to micro-level analyses, albeit in different ways (Entwisle 2007; Voss 2007).

\subsection{Geographically Weighted Regression}

Across the sciences, techniques have recently emerged for examining local relationships in data based on analytical approaches that focus on subsets of data (e.g., locally weighted scatterplot smoothing (LOWESS), a technique developed by Cleveland 1979). Techniques for the analysis of local spatial relationships also have been developed recently (for an overview, see Lloyd 2011).

The standard procedure in the vast majority of empirical analyses of spatial data is either to calculate a global statistic or to calibrate a global model. The term "global" implies that all of the data are used to compute a single statistic or model, and that the relationships between variables in the model are stationary across the study area. Such a procedure is flawed when the relationships being measured vary over space. Geographically Weighted Regression (GWR) is an exploratory statistical technique that allows for variations in relationships over space to be measured within a single modeling framework (Fotheringham, Brunsdon, and Charlton 2002). The output from GWR is a set of surfaces that can be mapped and measured, with each surface depicting the spatial variation of a relationship. Standard global modeling techniques, such as OLS or spatial regression methods, cannot detect nonstationarity, and thus their use 
may obscure regional or local variation in the relationships between predictors and the outcome variable. Public policy inferences based on results from global models in which nonstationarity is present but not detected may be quite poor in specific local/regional settings (Ali, Patridge, and Olfert 2007). It is important to note that GWR is an exploratory technique, and, as with ESDA and spatial econometric approaches, the insights gained from GWR can be utilized to improve model specification in global models. ${ }^{13}$

Several recent publications have demonstrated the analytical utility of GWR in demographic research. A paper by Işik and Pinarcioğlu (2006) illustrated the utility of GWR. Their investigation showed the unique spatial heterogeneities in fertility decline in the different regions of Turkey over the last few decades. In the absence of locally varying estimates, a model of fertility change in Turkey would look strikingly different from the local reality (Işik and Pinarcioğlu 2006). Others demographers have also utilized GWR. Johnson et al. (2005) used both global and local spatial statistics to look for spatio-temporal patterns in migration in the American Southwest. This approach allowed the investigators to examine dynamic migratory patterns of spatial and temporal clustering.

There have also been recent applications of GWR in health research. Edwards et al. (2010) and Fraser et al. (2012) looked at childhood obesity in two different parts of England (Leeds and Bristol, respectively), and showed that different covariates can be important in different regions. This implies that public health and policy research should take into account regional variations in the causes of health problems. A further example of the application of GWR in health research can be seen in a paper by Shoff et al. (2012). In their study on prenatal care utilization, the researchers illustrated how the nuanced nature of GWR can be useful for health care implementation. The study was supported by previous (mostly non-spatial) research, but allowed for more placespecific variation, which is important for on-the-ground planning and the implementation of policies (Shoff et al. 2012). Yang, Chen, and colleagues applied Poisson GWR regression to study the spatial nonstationarity of social determinants of cardiovascular mortality as a result of extreme (cold) weather events in Taiwan (Yang et al. 2009; Chen et al. 2010). In a recent paper, Gebreab and Diez Roux (2012) demonstrated the importance of using spatial heterogeneity when seeking to understand and eliminate racial disparities in coronary heart disease mortality between blacks and

\footnotetext{
${ }^{13}$ As noted by a reviewer, GWR papers that find that parameter coefficients vary across space have a tendency to focus on this result, but do not always seek to explain their results with further analyses. It is important that GWR and ESDA methods are utilized to help improve model specification, and that efforts be made to find explanations. This discussion parallels discussions of spatial scale, units of analysis, and the MAUP. It also reinforces the need to think about the geography of "effective" units prior to analysis, and also to experiment with different scales and aggregations (see also Flowerdew, Manley, and Sabel 2008, Riva et al. 2008, Mobley, Kuo, and Andrews 2008, and Spielman and Yoo 2009).
} 
whites across the United States. And Yang and Matthews (2012) used GWR on individual-level data to examine local variation in health service distrust among the elderly in Philadelphia.

GWR has been applied in other demography-related areas as well. Mennis and Jordan (2005) showed that the relationships among race, class, employment, urban concentration, and land use with air toxic release density in New Jersey vary significantly over space. Graif and Sampson (2009) were among the first researchers to utilize geographically weighted regression (GWR) methods in a study of crime; their findings suggested that the same neighborhood characteristics differentially predict homicide rates in different parts of Chicago.

Mennis (2006) observed that GWR analyses and interpretation are largely dependent on GWR maps, and that such maps can be problematic if they illustrate the size of parameter estimates while failing to illustrate their relative significance. This has been a problem in many early publications based on GWR methods (even in the classic text by Fotheringham, Brunsdon, and Charlton 2002). Using an empirical example, Mennis illustrated several potential methods for addressing these issues, including the use of multiple colors and varying hues (Mennis 2006) based on bivariate mapping techniques. The mapping of local GWR statistics by combining local parameter estimates and t-values on a single map is discussed further in Matthews and Yang (2012). Bivariate mapping techniques have recently been implemented in published research (e.g., Shoff et al. 2012; Chen et al. 2012).

There have, however, been certain drawbacks to using GWR. While GWR has been shown to be an extremely valuable tool, it can be extremely difficult to implement, especially in the case of large data sets. This is mainly because of two inherent problems. First, the construction of a GWR requires the calibration of the spatial weighting function (one for each different bandwidth, etc.). Second, for each bandwidth a new set of regressions are calculated for each location. Even if only one bandwidth is used, this process is computationally demanding. In most cases, it is necessary to optimize the bandwidth size because of a lack of a priori specification.

In a paper by Harris et al. (2010), the authors proposed a solution that incorporates several processors in order to "grid-enable" the process. Essentially, their solution is to run different aspects of the GWR on different processors. These processors could be stratified by bandwidth (since locations that are far apart are less likely to be related), and/or by the vectors in the distance matrix. After each processor has completed its component of the analysis, the results can be pooled for the final GWR analysis. One problem with doing either one or the other (bandwidth or matrix stratification) is that the distance weights are dependent on the bandwidth. The authors suggested that it would be computationally more efficient to recalculate the matrix for each iteration of the bandwidth optimization (Harris et al. 2010). Harris and colleagues then offered a 
case study using grid-enabled GWR in which $\mathrm{R}$ looked at several demographic characteristics in relation to higher education attainment. The results were not surprising, and the output was typical of GWR. What was, however, surprising was the size of the data set they were able to use for their analysis $(n=31,378)$. While the calculation of multiple regressions is the most computationally demanding component of GWR, in this case even the spatial matrix was enormous (matrix $=\mathrm{n}^{2}$ ). The ability to use such a large data set was even more impressive given the memory limitations associated with using R. Harris and colleagues were able to do this by remotely accessing several processors on the UK's National Grid infrastructure (NGS). Unfortunately, the NGS is only accessible by affiliates of UK universities and institutions, and funding for the multi R environment has been cut (Harris et al. 2010). ${ }^{14}$

GWR is an exploratory tool for exploring spatial nonstationarity (Páez, Long, and Farber 2008; Wheeler and Páez 2010). It is important to note that limitations associated with GWR model include multicollinearity, kernel bandwidth selection, and multiple hypothesis testing (Wheeler and Tiefelsdorf 2005; Wheeler 2007, 2009; Cho et al. 2009; Jiang et al. 2010; Páez, Farber, and Wheeler, 2011). Interested readers are encouraged to explore the R package gwrr (http://cran.r-project.org/web/packages/gwrr/ - authored by Wheeler) that includes diagnostic tests for collinearity in GWR models (see also Wheeler 2007).

\subsection{Multilevel modeling}

The emergence of multilevel modeling and the multilevel framework has generated what has been described as a "tidal wave" and an "explosion" of research in demography and social epidemiology (Pebley and Sastry 2004; Entwisle 2007; Glass and McAtee 2006). ${ }^{15}$ A methodological focus on multilevel or hierarchical modeling is relevant when examining the effects of contextual factors on social behavior played out at a lower level. It is also important when assessing to what extent individual behaviors and demographic and health outcomes are influenced by an individual's own characteristics, and by the attributes of the larger geographic area (i.e., a neighborhood or community, a village district, or state).

\footnotetext{
${ }^{14}$ Technological developments in data storage and handling will continue to change the nature, scale, and scope of data analysis. These developments are important but cannot be covered in this paper.

${ }^{15}$ Demography has a long-standing interest in context. For example, while most studies of maternal and child health outcomes focus on individual-level data from large-scale surveys, population scientists have a longestablished interest in contextual issues and multilevel modeling (Entwisle, Mason, and Hermalin 1986; Entwisle, Casterline, and Sayed 1989; Entwisle et al. 1997; Hirschman and Guest 1990; Pebley, Goldman, and Rodriguez 1996; Sastry 1996; Degraff, Bilsborrow, and Guilkey 1997; Stephenson and Tsui 2002).
} 
Multilevel models originated largely in education research, with its systematic collection of hierarchically nested data: students within classrooms, within schools, within school districts, etc. (Goldstein 2010). Some of the advances in multilevel modeling have come in the form of model estimation methods. Estimation for the multilevel model has frequently been done using Maximum Likelihood Estimation (MLE), Restricted Maximum Likelihood (RML), as well as Bayesian and bootstrapping methods. MLE depends on algorithms that are designed to iteratively step through potential values, recording the value at which the likelihood has reached its maximum. Such algorithms include the Newton-Raphson algorithm, the Fisher scoring algorithm, the EM algorithm, and the Iterative Generalized Least Squares method (Dedrick et al. 2009). RML uses maximum likelihood to estimate variance parameters, which are subsequently used to estimate fixed effects covariates. Both MLE and RML are dependent on large sample sizes. However, Bayesian estimation, frequently using the Gibbs sampler or other Markov Chain Monte Carlo (MCMC) simulation methods, offers an attractive alternative when sample sizes are small. However, the hefty computational demands associated with Bayesian methods make them hard to use when samples are large. Bootstrapping offers an alternative to dealing with uncertainty in variance and standard error estimation, especially in cases in which the data are nonnormal. The aforementioned methods of estimation have largely grown out of computational ability.

While the integration of individual and contextual data is a well established methodological area within population science (Entwisle 2007), some potential conceptual and technical challenges remain in integrating multilevel analyses techniques and GIS/spatial analysis (Subramanian, Jones, and Duncan 2003; Chaix, Merlo, and Chauvin 2005; Chaix et al. 2005; Macintyre and Ellaway 2003; Diez Roux 2003). To some extent, nested data are inherently spatial. Statistical methods that incorporate neighborhood, city, or regional effects are in essence considering the effects of places and spaces on their outcome(s) of interest (Jen, Jones, and Johnston 2009). Some of the advances along these lines have come in the form of understanding the proper measurements and definitions of such spaces (Chaix et al. 2009; Matthews 2011b). While traditional demography has looked at de jure classifications of place (census tracts, etc.), demographers are increasingly realizing that legal and political boundaries frequently have little to do with actual lived spaces. Furthermore, many social scientists and health researchers, as well as a growing number of population scientists, are working in regions that do not have synonymous spatial categories: that is, they are finding that neighborhoods and other administratively bounded areas may have different meanings in some of the non-industrialized and/or industrializing nations than they do in the developed world. 
Another way of investigating context is to look at the variation within areal units, rather than only the linear relationships between covariates and areal units. For example, research into neighborhood effects is popular in social epidemiology. Neighborhoods offer a context in which covariates can influence health outcomes in the individuals who live within their borders. However, it can be naïve to label neighborhoods as "healthy" or "unhealthy" since the variance in outcomes within a neighborhood can be extremely high. Therefore, the inclusion of measurements of variance in contextual effects is important, and can be included in multilevel models (Merlo et al. 2006).

Although it can be argued that multilevel modeling is inherently spatial, the inclusion of spatially explicit data, perhaps especially in demography, has been comparatively rare. However, a few studies have tried to integrate spatial and multilevel models. Among the most creative of these (and the closest coupling of the two approaches) is from Chaix and colleagues (Chaix et al. 2005; Chaix, Merlo, and Chauvin 2005). Rather than using arbitrary areas to define neighborhood contexts, the authors of this highly original paper operationalized neighborhood context as a "continuous" surface surrounding individual residences. Their spatial mixed models provided information not only on the magnitude, but also on the scale of spatial variations; and they provided more accurate standard errors for risk factor effects in studies of both mental disorders in Malmo (Sweden) and of health care utilization in France. For example, they found that place indicators better explained variations in health care utilization when measured across continuous space, rather than within an administrative area. Their work suggested that, in neighborhood studies, "a deeper understanding of the spatial variations in health outcomes may be gained by building notions of space into statistical models and measuring contextual factors across continuous space" (Chaix et al. 2005).

In another innovative paper, Borgoni and Billari (2003), noting the unlikely assumption of spatial independence in traditional multilevel models, used a spatially explicit approach in studying unprotected intercourse in Italian women. Divino and colleagues used a Bayesian method for dealing with mortality rates from small geographical regions and small populations, focusing on mortality rates in Italy for the year 1991 (Divino, Egidi, and Salvatore 2009). They incorporated a multilevel model that borrowed information from neighboring sub-regions in order to account for both spatial heterogeneity and homogeneity. Typically, such studies are plagued with problems relating to over-dispersion in settings of low intensity in mortality (in this instance, younger age groups).

Theoretical and conceptual models, based on socio-ecologic models or frameworks, rely on multilevel data structures that allow for an examination of individual behaviors embedded within hierarchical and non-hierarchical contexts (Glass 
and McAtee 2006; Entwisle 2007). In Glass and McAtee (2006), the potentially relevant processes operated at the micro, meso, and macro levels. The application of multilevel models in demography spans a wide array of core topics, and much research has been linked to the innovative utilization of new forms of data (e.g., satellite, built environment, crime) in which contextual attributes are derived from external data sources linked to the individual through shared geocodes, instead of being derived from the aggregation of individual data values observed within a higher level unit. We will return to the issue of the use of innovative geospatial data in our discussion of the papers in the special collection, and in our final section on the future of spatial demography.

\subsection{Spatial Pattern Analysis}

A wide range of methods now exist for analyzing spatial clusters of point data, such as disease or crime events (see Gatrell et al. 1996; Kulldorff 1997, 1998), in which the goal is to discover whether the observed events exhibit any systematic pattern, as opposed to being distributed at random within a study area. Point-based cluster detection methods include those developed to detect overall clustering in a study area, those used to identify cluster locations (elevated rates), and those used to assess clustering around point sources (e.g., a hazardous facility). The branch of statistical theory that deals with continuous field variables is geostatistics (Issaks and Srivastava 1989; Cressie 1993). Rather than focus on observations as the location of events, geostatistical methods aim to understand the spatial distribution of values of an attribute of interest over an entire study region, given values at fixed sampling points. Geostatistics is based on the assumption that at least some of the spatial variation in an attribute can be modeled by random processes with spatial autocorrelation, and can be used to provide accurate and reliable estimations of attribute values at locations in which no measurements are available. The developments in the materials and methods for geospatial data have facilitated the adoption, particularly in spatial epidemiology, of advanced techniques for spatial pattern analysis, spatiotemporal analysis, and Bayesian mapping and modeling (Gatrell et al. 1996; Elliott et al. 2001; Diggle 2003; Lawson, Brown, and Rodeiro 2003; Banajee, Carlin, and Gelfand 2004; Lawson 2006).

Recent applications of spatial pattern analysis techniques in demography include the use of kriging and the use of local statistics of spatial association (the $G^{*}$ statistic (Getis and Ord 1992; Ord and Getis 1995)) to study malaria transmission in the Brazilian Amazon (Singer and Castro 2001; Castro et al. 2006). This research, which is relevant to the crafting of malaria mitigation policies, included spatial statistical analysis. The results revealed that the early stages of frontier settlement are dominated 
by environmental risks related to ecosystem transformations that promote the larval habitats of Anopheles darlingi. As forests are cleared and agriculture, ranching, and urban development spread, malaria transmission is substantially reduced, and the risks of new infection are largely driven by human behavioral factors.

Urban sociologists have long been interested in the race and ethnic structure of neighborhoods and communities. The main methodological issues confronting researchers analyzing race/ethnic segregation revolve around the definition of geographic boundaries and segregation measures. Efforts to address these methodological issues have led to the development of new ways to explore and analyze segregation that focus on spatially derived measures and/or techniques. Applications of ESDA and of local statistical analysis to race/ethnic diversity and segregation can be found in Frank (2003), Brown, and Chung (2006); and in non-U.S. examples, such as in Borruso (2009) and in Johnston, Poulson, and Forrest (2010). Frank (2003) and Brown and Chung (2006) employed spatial autocorrelation and ESDA methods to describe and compare socioeconomic and racial residential patterns using global and local spatial statistics. Johnston and colleagues (2011) offered an innovative method for classifying "ethnoburbs," or wealthy sub-units of ethnic minorities nested within larger suburbs in New Zealand. Because these ethnoburbs have low population densities and are thus difficult to capture with global statistics, a localized method for studying them was introduced (Johnston, Poulson, and Forrest 2011).

The reliable and meaningful measurement of residential segregation is essential when studying the causes, patterns, and consequences of racial and socioeconomic segregation. Currently, the most common conceptualization of residential segregation is based on the dimension of evenness (Reardon and O'Sullivan 2004), and the most popular measure of residential segregation is, in general, the Index of Dissimilarity, $D$. This measure is computationally straightforward to calculate from census data. While the Index of Dissimilarity was originally applied to a comparison of two different population groups, most often whites and blacks, recent studies have extended this measure to the multi-group context (see Reardon and Firebaugh 2002 for an overview). Geographers have extended the Index of Dissimilarity in a different way by explicitly incorporating the spatial dimension (Wong 2002 2004). An emerging preference in the race/ethnic segregation literature is another evenness measure, the Entropy Index (or the Information Theory Index). The Entropy Index, referred to as Theil's $H$, measures the weighted average deviation of difference between an areal unit's group proportions and that of a larger area (e.g., metropolitan area). Entropy or race/ethnic diversity is greatest when each group is equally represented in the area. Two recent evaluations of segregation indices found that both the spatial and aspatial versions of $H$ are conceptually and mathematically superior to the more popular Index of Dissimilarity, $D$ 
(Reardon and Firebaugh 2002, Reardon and O'Sullivan 2004). The spatial $H$ has been defined and applied in Reardon et al. (2008) and in Lee et al. (2008).

In a very recent and highly innovative study, Spielman and Logan (2012) posed the following question: "How can we use the social composition of areas at different scales to identify neighborhoods and determine what defines them?" That is, using an eco-centric perspective, they explored how segregation (by socioeconomic indicators or race/ethnicity) can vary by spatial scale. They drew on 19th-century individual-level U.S. census data. By using individual-level data, researchers have the flexibility to study intergroup relations from a spatial perspective, unconstrained by administrative boundaries or by scale.

\section{Background to the Special Collection}

Inevitably, there are holes in the coverage of methodological topics that fall under the rubric of spatial demography. Our goal in Section 2 was not to be comprehensive, but rather to illustrate the main strengths of each focal technique, to point out some of the weaknesses and challenges that remain, and to synthesize the application of specific forms of spatial analysis to demographic research questions. We hope that these brief overviews achieved those aims. To further demonstrate the value of a spatial perspective in demographic research, we now briefly introduce the papers included in the Special Collection on "Spatial Demography."

The four main analytical areas described thus far (spatial econometrics, geographically weighted regression, multilevel modeling, and pattern analysis) formed the basis of a series of summer workshops offered at both Pennsylvania State University and the University of California Santa Barbara (2008-2011) ${ }^{16}$. The primary goal of these workshops was to teach and train researchers in specific techniques, thereby helping to create a cohort of scholars familiar with spatial thinking, geospatial data, and analytical methods. ${ }^{17}$ A more ambitious goal was to generate evidence that the

\footnotetext{
${ }^{16}$ The Advanced Spatial Analysis for Population Scientists workshop series was supported by a training grant from the Demographic and Behavioral Science Branch of the Eunice Kennedy Shriver National Institute of Human Health and Child Development. The NICHD Award R25 HD057002 - Principal Investigator: Stephen A. Matthews.

${ }^{17}$ As implied earlier in this paper, although it was possible to find training opportunities and resources to learn advanced spatial analysis methods in the university sector, the commercial sector, and from textbooks; the opportunities were limited, costly, and rarely targeted at population science research questions and applications. In 2005, we perceived a gap in the training of demography graduate students and other population scientists in the application of advanced spatial analysis methods. Our goal was to fill this training gap and to provide population scientists with exposure to advanced spatial analysis methods via a series of five-day workshops. Over four years, more than 200 participants attended our workshops. Some useful Internet resources focusing on mapping, analysis, and training can be found at the end of the reference list.
} 
workshops made a difference in the field of population science; specifically, that attendees would engage in demographic research that adopted spatial analytic tools. A call for papers targeting past workshop attendees was distributed in Spring 2011, with full papers to be submitted by September 1, 2011. The papers included in this Special Collection are a subset of the papers received. The common denominator of all of the submitted papers was that they were led by scholars early in their careers who participated in at least one of the four advanced spatial analysis workshops. ${ }^{18}$ In the remainder of this section, we provide a short overview of each paper.

While the diversity of methods available to spatial demographers cannot be captured in a handful of papers, these studies can provide a flavor of the methods that exist and of how they can be applied. Collectively, demographers investigate many different questions about many different types of places. Thus, it is no surprise that the published papers vary in terms of outcome and substantive theme, scale of analysis, geographical focus, the type of data used, the integration of data from multiple sources, ${ }^{19}$ temporal coverage, and the spatial analytical methods used. Moreover, as several papers used a combination of methods, even the grouping below (into the four main analytical areas) is somewhat arbitrary.

Spatial econometric papers: The obesity epidemic is very complex, and researchers, including demographers, are increasingly interested in exploiting new forms of spatial data and spatial analytic methods to measure and explain the role of "neighborhood' environments on obesity-related (and other health) outcomes. Duncan et al. (2012) used an explicitly spatial approach to evaluate the potential relationships between racial composition and socioeconomic disadvantage on neighborhood walkability in Boston, Massachusetts (U.S.A). Some neighborhoods are friendlier towards walking, and those that are friendlier are also more likely to have populations with better health (including mental health), higher degrees of social capital, and better economic incentives. Duncan and colleagues utilized exploratory spatial data analysis methods, such as the Moran's I statistic, to check for spatial autocorrelation in variables and in the residuals of Ordinary Least Squares regression models, as well as to estimate spatial lag and spatial error models (as needed). Their findings suggest that, in Boston, the percentage of black people in a neighborhood is negatively associated with walkability. Perhaps surprisingly, no significant relationship was found between

\footnotetext{
${ }^{18}$ Many of the submitted papers owe their origin to the workshops, and included collaborations between researchers who first met at these workshops. Other papers were based on ideas and ways of thinking about spatial data and analysis stimulated by the workshop (by workshop leaders and instructors, but also, and arguably most importantly, through interaction with other workshop attendees from different disciplines). While several papers were rejected during the review process, many of them are being revised and will likely be re-submitted to other demography and demography-related journals.

${ }^{19}$ While this is not the focus of the Special Collection, we wish to note that the level of innovation in data use and data integration is high in these papers. Demographic data have been linked to crime, housing, built environment, vegetation, and health data (among other types), and data have been simulated.
} 
walkability and either socioeconomic disadvantage or the percentage of the population who are Hispanic. This paper adds to the literature concerning neighborhood conditions, segregation, and health; perhaps especially because of its spatially explicit framework and testing.

Other papers in the Special Collection also used ESDA and spatial econometric frameworks, but these were often employed in conjunction with other techniques, particularly exploratory GWR methods (see below).

GWR papers: Shoff and Yang (2012) used a combination of OLS, exploratory GWR, and explanatory spatial econometrics (spatial regime modeling) to look at variation in the teenage birth rate across the United States. The U.S. has the highest teenage birth rate in the developed world, an anomaly that has long been a topic of discussion among researchers and policymakers alike. This study was one of the first to look at the entire U.S., and in particular to include a focus on the non-metropolitan areas of the country, which are on average less well served by the existing health infrastructure, and which offer limited economic and educational opportunities for adolescents and young adults. As extrapolating findings from metropolitan studies to nonmetropolitan areas can be problematic, it is important to understand how the same predictors may matter differently across different types of places. The use of GWR appears to offer both a theoretical and methodological advantage to the researchers, as local contexts can lead to different factors having varying relationships within different metropolitan/nonmetropolitan groupings. The authors used split-GWR models to explore the varying relationships between race/ethnic, religious, and socioeconomic factors and teenage birth rates. While noting that the use of split-GWR was interesting, the authors pointed out that it also presents new challenges and analytical issues (see earlier comments regarding more testing required of different GWR forms). The exploratory GWR analysis was used to justify the explanatory spatial regimes analysis. The authors divided the country into metropolitan and non-metropolitan "regimes," and were able to identify the varying role of the Socioeconomic Disadvantage Index on teen birth rates between metropolitan and non-metropolitan counties, with the index being shown to be significantly stronger in the former. These and other findings have implications for researchers and policymakers seeking to understand non-metropolitan teenage birth rates.

Arnio and Baumer (2012) utilized GWR, among other methods, to look at the interplay of demography and crime (specifically homicide, robbery, and burglary crimes), in the context of housing foreclosure in Chicago, Illinois, U.S.A., during the late-2000s. The authors provided a theoretical justification for expecting spatial heterogeneity in neighborhood crime. In this paper, the key demographic indicatorsimmigrant concentration, racial/ethnic composition, and measures of social inequality socioeconomic disadvantage - are on the right side of the regression equation. While 
the general relationships found between demographic factors, foreclosure, and crime were not too surprising, the use of both exploratory and explanatory techniques demonstrated the importance of "the local" fit as opposed to a one-size-fits-all "global" model. For example, the authors found that the relationship between social disadvantage and robbery, and also between residential stability and burglary, were both significantly negative and significantly positive depending upon where the local model was estimated. Thus, without a GWR model, a researcher or policymaker might miss some important local complexities in the relationship between demographics and crime.

Matthews and Yang (2012) is a paper accompanying this Special Collection. A major challenge to users of GWR methods is how best to present and synthesize the large number of mappable results, specifically the local parameter estimates and local $t$ values generated from local GWR models. The authors offered an elegant solution to this problem in which local parameter estimates and local $t$-values are simultaneously displayed on a single map based on the use of data selection and transparency techniques (applied to county-level mortality data in the U.S.). This method can help to focus attention on the areas of the map (regions, neighborhoods) in which the parameter estimates are statistically significant.

Multilevel model papers: Nawrotzki, Dickinson, and Hunter (2012) is an innovative demographic study that combined the Madagascar Demographic and Health Survey (2008/2009) with remote sensing data on vegetation cover to investigate whether access to livelihood capital (natural resources) differs between migrants and non-migrants in rural Madagascar. The data analysis was based on a two-level multilevel model framework (individuals within geographic clusters). The authors' findings demonstrated the importance of natural resources as a livelihood asset, regardless of migration status. The results indicated that migrants tend to have high levels of livelihood capital compared to non-migrants; and that, in areas with high levels of natural capital, migrants tend to have substantially higher levels of human capital than non-migrants. This is important, policy-relevant research that can be useful for identifying groups that should be targeted by livelihood-enhancing programs, as well as for designing policies that protect the natural resources and limit deforestation in disadvantaged rural communities.

Small-area estimation and point process papers: The highly relevant and understudied topic of spatial inequalities in child mortality within urban areas was taken on by Jankowska, Benza and Weeks (2012). The lack of geospatial data can present multiple methodological challenges. The authors addressed these challenges by leveraging multiple data sets and pooling date over time. They applied and tested a lowcost estimation method based on birth histories for creating small-area measures of mortality among children under age five in Accra, Ghana (across multiple time periods, 
1979-2006). They concluded that the low-cost estimation method has potential, but they acknowledged that more testing is needed to establish confidence intervals. The authors also compared the variability and trends in mortality among children under age five across 16 zones within Accra to a set of local environmental characteristics potentially linked to child mortality, such as housing quality/slum, vegetation, and health facilities. Interestingly, while the authors found the expected correlation between poorer environmental conditions and child mortality, they also found when examining trends over time that child mortality rates were improving in the poorest areas of the city, but were deteriorating in the higher SES areas. The authors suggested that these findings could be attributable to effective interventions in the slum or worst areas of the city, and to a lack of attention to the conditions found in some non-slum or disadvantaged neighborhoods (i.e., to women who might benefit from interventions but who live in areas that have often not qualified for or are excluded from interventions.) It is precisely this degree of intra-urban variation and nuanced local understanding that justifies investing in the development of small-area estimation methods of child health and mortality. This work can open up new research questions for demographers.

Almquist and Butts (2012). Demographic phenomena are frequently recorded at an aggregate level, limiting analysis of micro-social processes. The primary aim of this paper was to evaluate a method for simulating the distribution of households in small areal units in selected diverse contexts that represent urban, suburban, and rural areas. The authors used point process models (Poisson [uniform], low-discrepancy sequence [quasi-random], an inhomogeneous Poisson model [attraction]), and several statistical measures for point processes to compare the expected distribution of household locations to actual locations at three levels (i.e., block, block group, and tract) across the three diverse contexts. In all three areas, and for all three models, the block level was found to have been the most consistently simulated, while the attraction model appeared to have been superior in larger areal units. A qualitative examination indicated that for large areal units, urban areas were the most accurately simulated. The paper expanded the methodological application to include an example that simulated a network diffusion process over a spatially simulated network. This paper is of high practical value for demographic research, as it provides insight into methods for simulating household locations when such data are unavailable (or confidential).

\section{Discussion: The near future in spatial demography}

What does the near future hold for spatial demography? While demographers are well aware that it is dangerous to make predictions, we can predict with some confidence that things will change rapidly, as the geospatial data and methodological development 
environment is dynamic. Indeed, one of the main reasons why we chose to compile the Special Collection in Demographic Research is because the field has changed so much, even in the last few years (i.e., since recent academic reviews offered by Weeks 2004; Voss 2007; and Castro 2007).

While changes in data availability are not the focus of this paper, it must be emphasized that the volume, sources, and forms of geospatial data are growing rapidly. Recent developments in participant-generated data or volunteered geographical information (Goodchild 2007; Elwood, Goodchild, and Sui 2012) - that is, data from Twitter feeds through to global positioning system (GPS) traces-in next-generation wireless and sensor technologies, and in data storage and handling (e.g., cloud computing, geospatial data warehouses, data mining techniques, and relational databases) are already changing and will continue to change what, how, and when we collect data on individuals and their environments. New data formats will be tagged with both a geographic location and a time stamp, thus providing unparalleled spatial and temporal precision. Recent research suggests there will be a new generation of activity space studies that harness technologies-such as accelerometers, GPS, and smart phones - to engage in continuous monitoring of people in places (heart rate, physical activity, physical location), and/or in ecological momentary assessments of self-report measures of psychological health at specific times and places (for applications in sociology and demography, see Raento, Oulasvirta, and Eagle 2009; Palmer et al. forthcoming). These technological developments, as well as new spatiotemporal precision, have enormous potential to improve our functional understanding of human spatial behavior, and to contribute to new ways of thinking about relative and absolute utilization and/or exposure to place, as well as about issues of spatial embeddedness and of scales of analysis (Chaix et al. 2009; Matthews 2011b).

We also anticipate changes in how demographers conduct fieldwork as new data collection technologies fundamentally change the quality, scope, and flexibility of measures we collect and use for the social, built, and physical environments. That is, the collection of new types of individual and area-based geospatial data will greatly facilitate the measurement of appropriately defined contexts and individual exposure to contexts. In turn, this should generate closer links between theory, data, and method in the multilevel analysis of demographic and health outcomes (Entwisle 2007). Emerging statistical methods and new types of data coupled with reciprocal enhancements in conceptual models will help to promote spatially informed demographic research.

There is little doubt that the developments in data collection (e.g., the use of mobile computing, remote sensing, wireless technologies, and volunteered geographic information) foreshadow other innovative ways that geospatial data will be used in future demographic research. In some instances, the new forms of data will provide opportunities for more explicit spatial analysis using both exploratory methods and 
advanced spatial analytical tools such as those highlighted in this paper. But, as we have noted, methodological developments also are dynamic. The analytical arsenal is expanding rapidly: among the recent developments are spatial panel data models (Elhorst 2010), spatial filtering (Griffith 2010), Bayesian hierarchical modeling (Banerjee, Carlin, and Gelfand 2004), and spatial scan statistics (Jung, Kulldorff, and Klassen 2007). We have also recently seen the combination of methods that were previously separate. For example, a small number of scholars have explored the integration of quantile regression (Koenker 2005) with different spatial techniques, such as simultaneous autoregressive modeling and spatial lag hedonic modeling (Hallin, Lu, and Yu 2009; Kostov 2009; and Su and Yang 2007), M-quantile GWR (Salvati et al. 2007), and Bayesian spatially varying coefficient process modeling (Reich, Fuentes, and Dunson 2011). In addition, Chen et al. (2012) have developed a geographically weighted quantile regression (GWQR) method and have applied it to the study of spatial inequality and mortality in the United States.

An exciting research area is also emerging around the integration of detailed social and spatial networks (Entwisle et al. 2007; McCarty et al. 2007; Butts and Acton 2011). Yet another potentially interesting research area is forming around complex systems approaches and techniques, such as agent-based models, autonomous agent models, and micro-simulation. These approaches are filtering into many different fields of inquiry, and appear to have wide applicability in a field like demography (Bruch and Mare 2006). As we strive to gain a better understanding of levels of analysis, multilevel relationships, feedbacks, and interactions, these methods can help focus our conceptual thinking, and encourage the testing of alternative scenarios. With the right kinds of data, the adoption of complex systems dynamics will be explored more fully by demographers.

This paper has offered a brief introduction to some of the advanced spatial methods now available to demographers. The accompanying papers in this Special Collection provide more detail on these selected methods, applying them to important demographic research questions regarding teenage pregnancy in the U.S., child mortality in Accra (Ghana), segregation and health in Boston (U.S.A.), migration and rural livelihoods in Madagascar, settlement patterns in the U.S., and demographic correlates of crime in Chicago (U.S.A.). We expect that upcoming cohorts of demographers will increasingly utilize new forms of geospatial data and analyze them using spatially explicit methods. These shifts will ultimately be reflected in publications, as well as in grant applications that generate new demographic knowledge. 


\section{Acknowledgements}

This work was partially supported by the Advanced Spatial Analysis Training Program for Population Scientists (PI: Stephen Matthews, Penn State), an award from the Eunice Kennedy Shriver National Institute of Child Health and Human Development (R25HD057002). We thank Nyesha Black, Claudia Nau, Aggie Noah, Carla Shoff, and T.C. Yang for their comments and suggestions on our manuscript. All errors remain our own. 


\section{References}

Anderton, D.L., Anderson, A.B., Oakes, J.M., and Fraser, M.R. (1994). Environmental equity: The demographics of dumping. Demography 31(2): 229-248. doi:10.230 $7 / 2061884$.

Almquist, Z.W. and Butts, C.T. (2012). Point process models for household distributions within small areal units. Demographic Research 26(22): 593-632. doi:10.4054/DemRes.2012.26.22.

Anselin, L. (1988). Spatial econometrics, methods, and models. Dordrecht: Kluwer Academic.

Anselin, L. (2003). Spatial externalities, spatial multipliers, and spatial econometrics. International Regional Science Review 26(2): 153-166. doi:10.1177/0160 017602250972 .

Anselin, L. (2010). Thirty years of spatial econometrics. Papers in Regional Science 89(1): 3-25. doi:10.1111/j.1435-5957.2010.00279.x.

Anselin, L. and Le Gallo, J. (2006). Interpolation of air quality measures in hedonic house price models: Spatial aspects. Spatial Economic Analysis 1(1): 31-52. doi:10.1080/17421770600661337.

Anselin, L., Le Gallo J., and Jayet, H. (2008). Spatial panel econometrics. In: Matyas, L. and Sevestre, P. (eds.). The econometrics of panel data: Fundamentals and recent developments in theory and practice. Berlin Heidelberg: Springer: 625660. doi:10.1007/978-3-540-75892-1_19.

Anselin, L. and Rey, S. (2010). Perspectives on spatial data analysis. Berlin: Springer. doi:10.1007/978-3-642-01976-0.

Arnio A.N. and Baumer, E.P. (2012). Demography, foreclosure, and crime: Assessing spatial heterogeneity in contemporary models of neighborhood crime rates. Demographic Research 26(18): 449-488. doi:10.4054/DemRes.2012.26.18.

Austin, S.B., Melly, S.J., Sanchez, B.N., Patel, A., Buka, S., and Gortmaker, S.L. (2005). Clustering of fast-food restaurants around schools: A novel application of spatial statistics to the study of food environments. American Journal of Public Health 95(9): 1575-1581. doi:10.2105/AJPH.2004.056341.

Bailey, T.C. and Gatrell, A.C. (1996). Interactive spatial data analysis. Harlow, UK: Longman. 
Baller, R.D., Anselin, L., Messner, S.F., Deane, G., and Hawkins, D.F. (2001). Structural covariates of U.S. county homicide rates: Incorporating spatial effects. Criminology 39(3):561-590. doi:10.1111/j.1745-9125.2001.tb00933.x.

Banajee, S., Carlin, B.P., and Gelfand, A.E. (2004). Hierarchical modeling and analysis for spatial data. Boca Raton, FL: Chapman and Hall.

Bivand, R.S., Pebesma E.J., and Gómez-Rubio, V. (2008). Applied spatial data analysis with $R$. New York: Springer.

Borgoni, R. and Billari, F.C. (2003). Bayesian spatial analysis of demographic survey data: An application to contraceptive use at first sexual intercourse. Demographic Research 8(3): 61-92. doi:10.4054/DemRes.2003.8.3.

Borruso, G. (2009). Geographical analysis of foreign immigration and spatial pattern in urban areas: density estimation, spatial segregation and diversity analysis. In: Gavrilova, M.L. and Tan, C.J.K. (eds.). Lecture notes in computer science (LNCS):Transactions on computational science VI. Berlin: Springer-Verlag: 301-323. doi:10.1007/978-3-642-10649-1_18.

Brown, L.A. and Chung, S. (2006). Spatial segregation, segregation indices and the geographical perspective. Population, Space and Place 12(2): 125-143. doi:10.1002/psp.403.

Bruch, E.E. and, Mare, R.D. (2006). Neighborhood choice and neighborhood change. American Journal of Sociology 112(3): 667-709. doi:10.1086/507856.

Butts, C.T. and Acton, R.M. (2011) Spatial modeling of social networks. In: Nyerges, T.L., Couclelis, H., and McMaster, R. (eds.). The SAGE handbook of GIS and society. Thousand Oaks, CA: SAGE. 222-250. doi:10.4135/9781446201046. n12.

Butz, W. and Torrey, B.B. (2006). Some frontiers in social science. Science 312(5782): 1898-1900. doi:10.1126/science.1130121.

Castro, M. (2007). Spatial demography: An opportunity to improve policy making at diverse decision levels. Population Research and Policy Review 26(5): 477-509. doi:10.1007/s11113-007-9041-x.

Castro, M., Monte-Mór, R.L., Sawyer, D.O., and Singer, B.H. (2006). Malaria risk on the Amazon frontier. Proceedings of the National Academy of Sciences 103(7): 2452-2457. doi:10.1073/pnas.0510576103. 
Chaix, B., Merlo, J., Evans, D. Leal, C., and Havard, S. (2009). Neighborhoods in ecoepidemiologic research: Delimiting personal exposure areas: A response to Riva, Gauvin, Apparicio and Brodeur. Social Science \& Medicine 69 (9): 1306-1310. doi:10.1016/j.socscimed.2009.07.018.

Chaix, B., Merlo, J., Subramanian, S.V., Lynch, J., and Chauvin, P. (2005). Comparison of a spatial perspective with a multilevel analytical approach in neighborhood studies: the case of mental and behavioral disorders due to psychoactive substance use in Malmö, Sweden, 2001. American Journal of Epidemiology 162(2): 171-182. doi:10.1093/aje/kwi175.

Chaix, B., Merlo, J., and Chauvin, J. (2005). Comparison of a spatial approach with the multilevel approach for investigating place effects on health: The example of healthcare utilization in France. Journal of Epidemiology and Community Health 59: 517-526. doi:10.1136/jech.2004.025478.

Chen, V.Y-J., Den, W-S., Yang, T-C., and Matthews, S.A. (2012). Geographically weighted quantile regression (GWQR): An application to US mortality data. Geographical Analysis 44(2): 134-150. doi:10.1111/j.1538-4632.2012.00841.x.

Chen, V.Y-J., Wu, P-C., Yang, T-C., and Su H-J. (2010). Examining non-stationary effects of social determinants on cardiovascular mortality after cold surges in Taiwan. Science of the Total Environment 408(9): 2042-2049. doi:10.1016/ j.scitotenv.2009.11.044.

Chi, G. and Zhu, J. (2008). Spatial regression models for demographic analysis. Population Research and Policy Review 27(1): 17-42. doi:10.1007/s11113-0079051-8.

Cho, S., Lambert, D.M., Kim, S.G., and Jung, S. (2009). Extreme coefficients in geographically weighted regression and their effects on mapping. GIScience \& Remote Sensing 46(3): 273-288. doi:10.2747/1548-1603.46.3.273.

Cleveland, W.S. (1979). Robust locally weighted regression and smoothing scatterplots. Journal of the American Statistical Association 74(368): 829-836. doi:10.1080/01621459.1979.10481038.

Cressie, N. (1991). Statistics for spatial data. New York, NY: John Wiley and Sons.

Cromley, E.K. and McLafferty, S.L. (2002). GIS and public health. New York: Guilford Press.

Cromley, E.K. and McLafferty, S.L. (2011). GIS and public health (second edition). New York: Guilford Press. 
Dedrick, R.F., Ferron, J.M., Hess, M.R., Hogarty, K.Y., Kromrey, J.D., Lang, T.R., Niles, J.D., and Lee, R.S. (2009). Multilevel modeling: A review of methodological issues and applications. Review of Educational Research 79(1): 69-102. doi:10.3102/0034654308325581.

Degraff, D.S., Bilsborrow, R.E., and Guilkey, D.K. (1997). Community-level determinants of contraceptive use in the Philippines: A structural analysis. Demography 34(3): 385-398. doi:10.2307/3038291.

De Jong, G.F., Roempke Graefe, D., Irving, S.K., and St. Pierre, T. (2006). Measuring state TANF policy variations and change after reform. Social Science Quarterly 87(4): 755-781. doi:10.1111/j.1540-6237.2006.00432.x.

De Smith, M.J., Goodchild M.F., and Longley, P.A. (2007). Geospatial analysis. Leicester, UK: The Winchelsea Press, Troubador Publishing Limited.

Diez Rouz, A.V. (2003). The examination of neighborhood effects on health: Conceptual and methodological issues related to the presence of multiple levels of organization. In: Kawachi, I. and Berkman, L.F. (eds.). Neighborhoods and health. New York, NY: Oxford University Press: 45-64. doi:10.1093/acprof:oso/ 9780195138382.003.0003.

Diggle, P.J. (2003). Statistical analysis of spatial point patterns. London, UK: Arnold Publishers.

Divino, F., Egidi, V., and Salvatore, M.A. (2009). Geographical mortality patterns in Italy. Demographic Research 20(18): 435-466. doi:10.4054/DemRes.2009.20. 18.

Duncan, D.T., Aldstadt, J., Whalen, J., White, K., Castro M.C., and Williams, D.R. (2012). Space, race, and poverty: Spatial inequalities in walkable neighborhood amenities? Demographic Research 26(17): 409-448. doi:10.4054/DemRes.2012. 26.17 .

Echávarri, R.A. and Ezcurra, R. (2010). Education and gender bias in the sex ratio at birth: Evidence from India. Demography 47(1): 249-268. doi:10.1353/dem.0.00 89.

Edwards, K., Clarke, G., Ransley, J.K., and Cade, J. (2010). The neighbourhood matters: studying exposures relevant to childhood obesity and the policy implications in Leeds, UK. Journal of Epidemiology and Community Health 64(3): 194-201. doi:10.1136/jech.2009.088906. 
Elhorst, J.P. (2003). Specification and estimation of spatial panel data models. International Regional Science Review 26(3): 244-268. doi:10.1177/0160017603 253791.

Elhorst, J.P. (2010). Spatial panel data models. In: Fischer M.M. and Getis, A. (eds.). Handbook of applied spatial analysis: Software, tools, methods and applications. Berlin: Springer: 377-407. doi:10.1007/978-3-642-03647-7_19.

Elliot, P., Wakefield, J., Best, N., and Briggs, D. (2001). Spatial epidemiology: Methods and applications. Oxford, UK: Oxford University Press. doi:10.1093/acprof:oso/9780198515326.001.0001.

Elwood, S., Goodchild M.J., and Sui, D. (2012). Researching Volunteered Geographic Information: Spatial data, geographical research, and new social practice. Annals of the Association of American Geographers 102(3): 571-590. doi:10.1080/00045608.2011.595657.

Entwisle, B. (2007). Putting people into place. Demography 44(4): 687-703. doi:10.1353/dem.2007.0045.

Entwisle, B. (2011). Spatial demography: Opportunities and challenges. Paper presented at the Future directions in spatial demography specialist meeting, Santa Barbara, CA, December 2011. http://ncgia.ucsb.edu/projects/spatialdemography.

Entwisle, B., Casterline, J.B., and Sayed, H.A.A. (1989). Villages as context for contraceptive behavior in rural Egypt. American Sociological Review 54(6): 1019-1034. doi:10.2307/2095721.

Entwistle, B., Faust, K., Rindfuss, R.R., and Kenada T. (2007). Networks and contexts: Variation in the structure of social ties. American Journal of Sociology 112(5): 1495-1533. doi:10.1086/511803.

Entwisle, B., Mason, W.M., and Hermalin, A.I. (1986). The multilevel dependence of contraceptive use on socioeconomic development and family planning program strength. Demography 23(2): 199-216. doi:10.2307/2061616.

Entwisle, B., Rindfuss, R.R, Walsh, S.J., Evans, T.P., and Curran, S.R. (1997). Geographic information systems, spatial network analysis, and contraceptive choice. Demography 34(2): 171-187. doi:10.2307/2061697.

Fingleton, B. (2008). A generalized method of moments estimator for a spatial panel model with an endogenous spatial lag and spatial moving average errors. Spatial Economic Analysis 3(1): 27-44. doi:10.1080/17421770701774922. 
Fischer, M.M. and Getis, A. (2010). Handbook of applied spatial analysis: Software tools, methods and applications. Berlin: Springer. doi:10.1007/978-3-64203647-7.

Flowerdew, R., Manley, D.J., and Sabel, C.E. (2008). Neighborhood effects on health: Does it matter where you draw the boundaries. Social Science \& Medicine 66(6): 1241-1255. doi:10.1016/j.socscimed.2007.11.042.

Fotheringham, A.S., Brunsdon, C., and Charlton, M.E. (2002). Geographically weighted regression: The analysis of spatially varying relationships. Chichester, UK: John Wiley \& Sons.

Fotheringham, A.S. (2009). Geographically weighted regression. In: Fotheringham, A.S. and Rogerson, P.A. (eds.). The SAGE handbook of spatial analysis. Thousand Oaks, CA: SAGE: 243-253.

Fotheringham, A.S. and Rogerson, P.A. (2009). The SAGE handbook of spatial analysis. Thousand Oaks, CA: SAGE.

Frank, A.I. (2003). Using measures of spatial autocorrelation to describe socioeconomic and racial residential patterns in US urban areas. In: Kidner, D., Higgs, G., and White, S. (eds.). Socio-economic applications of geographic information science (Innovations in GIS 9). London, UK: Taylor and Francis: 147-162.

Fraser, L.K., Clarke, G.P., Cade, J.E, and Edwards, K.L. (2012). Fast food and obesity: A spatial analysis in a large United Kingdom population of children aged 13-15. American Journal of Preventive Medicine 42(5): e77-e85. doi:10.1016/j.amepre. 2012.02.007.

Friedman, S., and Lichter, D.T. (1998). Spatial inequality and poverty among American children. Population Research and Policy Review 17(2): 91-109. doi:10.1023/A:1005740205017.

Gatrell, A.C., Bailey, T.C., Diggle, P.J., and Rowlingson, B.S. (1996). Spatial point pattern analysis and its application in geographical epidemiology. Transactions Institute of British Geographers 21(1): 256-274. doi:10.2307/622936.

Gebreab, S.Y. and Diez Roux, A.V. (2012). Exploring racial disparities in CHD mortality between blacks and whites across the United States: A geographically weighted regression approach. Health \& Place 18(5): 1006-1014. doi:10.1016/j.healthplace.2012.06.006. 
Glass, T.A. and McAtee, M.J. (2006). Behavioral science at the crossroads in public health: Extending horizons, envisioning the future. Social Science \& Medicine 62(7): 1650-1671. doi:10.1016/j.socscimed.2005.08.044.

Goldstein, H. (2010). Multilevel statistical models. New York, NY: Wiley. doi:10.1002/ 9780470973394 .

Goodchild, M.F. (2007). Citizens as sensors: The world of volunteered geography. GeoJournal 69(4): 211-221. doi:10.1007/s10708-007-9111-y.

Goodchild, M.F., Anselin, L., Applebaum, R.P., and Herr Harthorn, B. (2000). Toward spatially integrated social science. International Regional Science Review 23(2): 139-159. doi:10.1177/016001760002300201.

Goodchild, M.F. and Janelle, D.G. (2004). Spatially integrated social science. New York, NY: Oxford University Press.

Goodchild, M.F. and Janelle, D.G. (2010). Toward critical spatial thinking in the social sciences and humanities. GeoJournal 75(1): 3-13. doi:10.1007/s10708-0109340-3.

Graif, C. and Sampson, R.J. (2009). Spatial heterogeneity in the effects of immigration and diversity on neighborhood homicide rates. Homicide Studies 13(3): 242-260. doi:10.1177/1088767909336728.

Harris, R., Singleton, A., Grose, D., Brunsdon, C., and Longley, P.A. (2010). Grid enabling geographically weighted regression: A case study of participation in higher education in England. Transactions in GIS 14(1): 43-61. doi:10.1111/j.1467-9671.2009.01181.x.

Haining, R. (2003). Spatial Data Analysis: Theory and Practice. Cambridge, UK: Cambridge Univ. Press. doi:10.1017/CBO9780511754944.

Hallin, M., Lu, Z., and Yu, K. (2009). Local linear spatial quantile regression. Bernoulli 15(3): 659-686. doi:10.3150/08-BEJ168.

Hirschman, C., and Guest, A. (1990). Multilevel models of fertility determination in four southeast Asian countries: 1970 and 1980. Demography 27(3): 369-396. doi: $10.2307 / 2061374$.

Işik, O., and Pinarcioğlu, M.M. (2006). Geographies of a silent transition: A geographically weighted regression approach to regional fertility differences in Turkey. European Journal of Population/Revue européenne de Démographie 22(4): 399-421. 
Issaks, E.H., and Srivastava, R.M. (1989). An introduction to applied geostatistics. Oxford, UK: Oxford University Press.

Jankowska, M.M., Benza, M., and Weeks, J. (2012). Estimating spatial inequalities of urban child mortality. Demographic Research 28(2): 33-62. doi:10.4054/ DemRes.2013.28.2.

Jen, M.H., Jones, K., and Johnston, R. (2009). Compositional and contextual approaches to the study of health behaviour and outcomes: Using multi-level modelling to evaluate Wilkinson's income inequality hypothesis. Health \& Place 15(1): 198-203. doi:10.1016/j.healthplace.2008.04.005.

Jiang, B., Yao, X., and Wheeler, D.C. (2010). Visualizing and diagnosing coefficients from geographically weighted regression models. In: Sui, D.Z., Tietze, W., Claval, P., Gradus, Y., Park, S.O., and Wusten, H. (eds.). Geospatial analysis and modelling of urban structure and dynamics. Netherlands: Springer: 415-436. doi:10.1007/978-90-481-8572-6.

Johnson, K.M., Voss, P.R., Hammer, R.B., Fuguitt, G.V., and Mcniven, S. (2005). Temporal and spatial variation in age-specific net migration in the United States. Demography 42(4): 791-812. doi:10.1353/dem.2005.0033.

Johnston, R., Poulsen, M., and Forrest, J. (2011) Using spatial statistics to identify and characterise ethnoburbs: Establishing a methodology using the example of Auckland, New Zealand. GeoJournal 76(5): 447-467. doi:10.1007/s10708-0109366-6.

Jung I., Kulldorff, M., and Klassen, A. (2007). A spatial scan statistic for ordinal data. Statistics in Medicine 26(7): 1594-1607. doi:10.1002/sim.2607.

Kelejian, H. H., and Prucha, I.R. (2002). 2SLS and OLS in a spatial autoregressive model with equal spatial weights. Regional Science and Urban Economics 32(6): 691-707. doi:10.1016/S0166-0462(02)00003-0.

Kelejian, H.H., and Prucha, I.R. (2007). The relative efficiencies of various predictors in spatial econometric models containing spatial lags. Regional Science and Urban Economics 37(3): 363-374. doi:10.1016/j.regsciurbeco.2006.11.005.

Koenker, R. (2005). Quantile regression. Cambridge: Cambridge University Press. doi:10.1017/CBO9780511754098.

Kostov, P.A. (2009) Spatial quantile regression hedonic model of agricultural land prices. Spatial Economic Analysis. 4(1): 53 - 72. doi:10.1080/1742177080262 5957. 
Kulldorff, M. (1997). A spatial scan statistic. Communications in Statistics: Theory and Methods 26(6): 1481-1496. doi:10.1080/03610929708831995.

Kulldorff, M. (1998). Statistical methods for spatial epidemiology. In: Gatrell A.C. and Loytonen, M. (eds.). GIS and health. London, UK: Taylor and Francis: 42-69.

Lawson, A.B. (2006). Statistical methods in spatial epidemiology. New York, NY: John Wiley and Sons.

Lawson, A.B., Browne, W.J., and Vidal Rodeiro, C.L. (2003). Disease mapping with WinBUGS and MLwiN. New York, NY: John Wiley and Sons. doi:10.1002/ 0470856068 .

Lee, B.A., Reardon, S.F., Firebaugh, G., Farrell, C.R., Matthews, S.A., and O'Sullivan, D. (2008). Beyond the census tract: Patterns and determinants of racial segregation at multiple geographic scales. American Sociological Review 73(5): 766-791. doi:10.1177/000312240807300504.

Lee, L.F. (2003). Best spatial two stage least squares estimators for a spatial autoregressive model with autoregressive disturbances. Econometric Reviews 22(4): 307-335. doi:10.1081/ETC-120025891.

Lee, L.F. (2004). Asymptotic distributions of quasi-maximum likelihood estimators for spatial autoregressive models. Econometrica 72(6): 1899-1925. doi:10.1111/ j.1468-0262.2004.00558.x.

Lee, L.F. (2007). GMM and 2SLS estimation of mixed regressive, spatial autoregressive models. Journal of Econometrics 137(2): 489-514. doi:10.1016/ j.jeconom.2005.10.004.

LeSage, J.P., and Pace, R.K. (2007). A matrix exponential spatial specification. Journal of Econometrics 140(1): 190-214. doi:10.1016/j.jeconom.2006.09.007.

LeSage, J.P, and Pace, R.K. (2009). Introduction to spatial econometrics. Boca Raton, FL: CRC. doi:10.1201/9781420064254.

Liverman, D., Moran, E.F., Rindfuss R.R., and Stern, P.C. (1998). People and pixels: Linking remote sensing and social science. Washington D.C.: National Academy Press.

Lloyd, C. (2011). Local models for spatial analysis (Second Edition). Boca Raton, FL: CRC Press.

Logan, J.R. (2012) Making a place for space: Spatial thinking in social science. Annual Reviews of Sociology 38: 507-524. doi:10.1146/annurev-soc-071811-145531. 
Logan, J.R., Zhang, W., and Xu, H. (2010). Applying spatial thinking in social science research. GeoJournal 75(1): 15-27. doi:10.1007/s10708-010-9343-0.

Macintyre, S., and Ellaway, A. (2003). Neighborhoods and health: An overview. In Kawachi, I., and Berkman, L.F. (eds.). Neighborhoods and health. New York, NY: Oxford University Press. 20-42.

Matthews, S.A. (2011a). Spatial analysis. Oxford Bibliographies Online - Sociology. http://www.oxfordbibliographiesonline.com/view/document/obo-9780199756 384/obo-9780199756384-0058.xml.

Matthews, S.A. (2011b). Spatial polygamy and the heterogeneity of place: studying people and place via egocentric methods. In: Burton, L., Kemp, S., Leung, M., Matthews, S.A., and Takeuchi, D. (eds.). Communities, neighborhoods, and health: Expanding the boundaries of place. New York: Springer: 35-55.

Matthews, S.A. (2012). Thinking about place, spatial behavior, and spatial processes in childhood obesity. American Journal of Preventive Medicine 42(5): 516-520. doi:10.1016/j.amepre.2012.02.004.

Matthews, S.A., Janelle, D.G., and Goodchild, M.F. (2007). Advanced Spatial Analysis Training for Population Scientists. University Park, PA: Penn State Population Research Institute. http://www.pop.psu.edu/services/GIA/ training-resources

Matthews, S.A., Janelle, D.G., and Goodchild, M.F. (2012). Future directions in spatial demography: Final report. (Final Report of a Specialist Meeting held December 12-13, 2011). http://ncgia.ucsb.edu/projects/spatial-demography/.

Matthews, S.A., Moudon, A.V., and Daniel, M. (2009). Using geographic information systems (GIS) for enhancing research relevant to policy on diet, physical activity, and weight. American Journal of Preventive Medicine 36(4S): 171-176. doi:10.1016/j.amepre.2009.01.011.

Matthews, S.A., and Yang, T.-C. (2012). Mapping the results of local statistics: Using geographically weighted regression. Demographic Research 26(6): 151-166. doi:10.4054/DemRes.2012.26.6.

McCarty, C., Molina, J.L., Aguilar, C., and Rota, L. (2007). A comparison of social network mapping and personal network visualization. Field Methods 19(2): 145-162. doi:10.1177/1525822X06298592.

Menken, J., Blanc, A.K., and Lloyd, C.B. (eds.). (2002). Training and support of developing-country population scientists: A panel report. New York: Population Council. 
Mennis, J. (2006). Mapping the results of geographically weighted regression. The Cartographic Journal 43(2): 171-179. doi:10.1179/000870406X114658.

Mennis, J.L., and Jordan, L. (2005). The distribution of environmental equity: Exploring spatial nonstationarity in multivariate models of air toxic releases. Annals of the Association of American Geographers 95(2): 249-268. doi:10.1111/j.1467-8306.2005.00459.x.

Merlo, J., Chaix, B., Ohlsson, H., Beckman, A., Johnell, K., Hjerpe, P., Rastam, L., and Larsen K. (2006). A brief conceptual tutorial of multilevel analysis in social epidemiology: Using measures of clustering in multilevel logistic regression to investigate contextual phenomena. Journal of Epidemiology and Community Health 60(4): 290-297. doi:10.1136/jech.2004.029454.

Messner, S.F., Anselin, L., Baller, R.D., Hawkins, D.F., Deane, G., and Tolnay, S.E. (1999). The spatial patterning of county homicide rates: An application of exploratory spatial data analysis. Journal of Quantitative Criminology 15(4): 423-450. doi:10.1023/A:1007544208712.

Mobley, L.R., Kuo, T., and Andrews, L.S. (2008). How sensitive are multilevel regression findings to defined area of context? A case study of mammography use in California. Medical Care Research and Review 65: 315-337.

Morland, K., Wing, S., Diez Roux, A.V., and Poole, C. (2002). Neighborhood characteristics associated with the location of food stores and food service places. American Journal of Preventive Medicine 22(1): 23-29. doi:10.1016/ S0749-3797(01)00403-2.

Morenoff, J.D. (2003). Neighborhood mechanisms and the spatial dynamics of birth weight. American Journal of Sociology 108(5): 976-1017. doi:10.1086/374405.

Morenoff, J.D., Sampson, R.J., and Raudenbush, S.W. (2001). Neighborhood inequality, collective efficacy, and the spatial dynamics of urban violence. Criminology 39(3): 517-558. doi:10.1111/j.1745-9125.2001.tb00932.x.

Namboodiri, K. (1991). Demographic analysis: A stochastic approach. San Diego, CA: Academic Press Inc. Harcourt Brace Jovanovich, Publishers.

National Institute of Child Health and Human Development. (2002). Demographic and Behavioral Sciences Branch, goals and opportunities: 2002-2006. Bethesda, MD: Demographic and Behavioral Sciences Branch, Center for Population Research, NICHD. 
Nawrotzki, R., Dickinson, T.W., and Hunter, L.M. (2012). Natural resources and natural livelihoods: Differences between migrants and non-migrants in Madagascar. Demographic Research 26(24): 661-700. doi:10.4054/DemRes. 2012.26.24.

Openshaw, S. (1984). The modifiable areal unit problem. Norwich, UK: GeoBooks.

O'Sullivan, D., and Unwin, D.J. (2010). Geographic information analysis. Hoboken, NJ: John Wiley.

Páez, A., Farber, S., and Wheeler, D.C. (2011). A simulation-based study of geographically weighted regression as a method for investigating spatially varying relationships. Environment and Planning A. 43(12): 2992-3010. doi:10.1068/a44111.

Páez, A., Long F., and Farber, S. (2008). Moving window approaches for hedonic price estimation: An empirical comparison of modelling techniques. Urban Studies 45(8): 1565-1581. doi:10.1177/0042098008091491.

Pais, J.F., and Elliott, J.R. (2008). Places as recovery machines: Vulnerability and neighborhood change after major hurricanes. Social Forces 86(4): 1415-1453. doi:10.1353/sof.0.0047.

Palmer, J.R.B., Espenshade, T.J., Bartumeus, F., Chung, C.Y., Ozgencil, N.E., and Li, K. (Forthcoming). New approaches to human mobility: Using mobile phones for demographic research. Demography.

Pebley, A., and Sastry, N. (2004). Neighborhoods, poverty, and children's wellbeing. In: Neckerman, K.M. (ed.). Social inequality. New York, NY: Russell Sage Foundation: 119-145.

Pebley, A.R., Goldman, N., and Rodriguez, G. (1996). Prenatal and delivery care and childhood immunization in Guatemala: Do family and community matter? Demography 33(2): 231-247. doi:10.2307/2061874.

Plane, D.A. and Rogerson, P.A. (1994). The geographical analysis of population: With applications to planning and business. New York, NY: John Wiley \& Sons.

Raento, M., Oulasvirta, A., and Eagle, N. (2009). Smartphones: An emerging tool for social scientists. Sociological Methods and Research 37(3): 426-454. doi:10.1177/0049124108330005.

Rees, P.H., and Wilson, A.G. (1977). Spatial population analysis. London, UK: Edward Arnold. 
Reich, B.J., Fuentes, M., and Dunson, D.B. (2011). Bayesian spatial quantile regression. Journal of the American Statistical Association 106(493): 6-20. doi:10.1198/jasa.2010.ap09237.

Reardon, S.F. and Firebaugh, G. (2002). Measures of multigroup segregation. Sociological Methodology 32(1): 33-67. doi:10.1111/1467-9531.00110.

Reardon, S.F., Matthews, S.A., O’Sullivan, D., Lee, B.A., Firebaugh, G., Farrell, C.R., and Bischoff, K. (2008). The geographic scale of metropolitan racial segregation. Demography 45(3): 489-514. doi:10.1353/dem.0.0019.

Reardon, S.F. and O'Sullivan, D. (2004). Measures of spatial segregation. Sociological Methodology 34(1): 121-162. doi:10.1111/j.0081-1750.2004.00150.x.

Robinson, A.H., (1982). Early thematic mapping in the history of cartography. Chicago, IL: The University of Chicago Press.

Rogers, A. (1975). Introduction to multiregional mathematical demography. New York, NY: John Wiley.

Rogers, A. (1995). Multiregional demography: Principles, methods and extensions. New York, NY: John Wiley.

Saelens, B.E., Sallis, J.F., Black, J.B., and Chen, D. (2003). Neighborhood-based differences in physical activity: An environment scale evaluation. American Journal of Public Health 93(9): 1552-1558. doi:10.2105/AJPH.93.9.1552.

Salvati N., Tzavidis, N., Pratesi, M., and Chambers, R. (2007). Small area estimation via M-quantile geographically weighted regression. Wollongong, Australia: Centre for Statistical and Survey Methodology, University of Wollongong. (CSSM Working Paper Series 14-08).

Sampson, R.J., Morenoff, J.D., and Earls, F. (1999). Beyond social capital: Spatial dynamics of collective efficacy for children. American Sociological Review 64(5): 633-660. doi:10.2307/2657367.

Sastry, N. (1996). Community characteristics, individual and household attributes, and child survival in Brazil. Demography 33(2): 211-229. doi:10.2307/2061873.

Savitz, N.V. and Raudenbush, S.W. (2009). Exploiting spatial dependence to improve measurement of neighborhood social processes. Sociological Methodology 39(1): 151-183. doi:10.1111/j.1467-9531.2009.01221.x.

Schabenberger, O. and Gotway, C.A. (2005). Statistical methods for spatial data analysis. Boca Raton, FL: Chapman and Hall/CRC. 
Shoff, C. and Yang, T.-C. (2012). Spatially varying predictors of teenage birth rates among counties in the United States. Demographic Research 27(14): 377-418. doi:10.4054/DemRes.2012.27.14.

Shoff, C., Yang, T.-C., and Matthews, S.A. (2012). What has geography got to do with it? Using GWR to explore place-specific associations with prenatal care utilization. GeoJournal. 77(3): 331-341. doi:10.1007/s10708-010-9405-3.

Spielman, S.E., and Logan, J.R. (2012) Using high resolution population data to identify neighborhoods and determine their boundaries. Annals of the Association of American Geographers 103(1): 67-84. doi:10.1080/00045608. 2012.685049 .

Spielman, S.E., and Yoo, E.-h. (2009). The spatial dimensions of neighborhood effects. Social Science and Medicine 68(6): 1098-1105. doi:10.1016/j.socscimed.2008. 12.048 .

Stephenson, R., and Tsui, A.O. (2002). Contextual influences on reproductive health service use in Uttar Pradesh, India. Studies in Family Planning 33(4): 309-320. doi:10.1111/j.1728-4465.2002.00309.x.

Su, L., and Yang, Z. (2007). Instrumental variable quantile estimation of spatial autoregressive models. Singapore: Singapore Management University, School of Economics. (Research Collection School of Economics Paper 1074)

Subramanian, S.V., Jones, K., and Duncan, C. (2003). Multilevel methods for public health research. In: Kawachi, I., and Berkman, L.F. (eds.). Neighborhoods and health. New York, NY: Oxford University Press: 65-111.

Voss, P.R. (2007a). Demography as a spatial social science. Population Research and Policy Review 26(5-6): 457-476. doi:10.1007/s11113-007-9047-4.

Voss, P.R. (2007b) Introduction to the special issue on spatial demography. Population Research and Policy Review 26(5-6): 455-456. doi:10.1007/s11113-007-9048-3.

Voss, P.R., Long, D.D., Hammer, R.B., and Friedman, S. (2006). County child poverty rates in the US: A spatial regression approach. Population Research and Policy Review 25(4): 369-391. doi:10.1007/s11113-006-9007-4.

Wachter, K.W. (2005). Spatial demography. Proceedings of the National Academy of Sciences 102(43): 15299-15300. doi:10.1073/pnas.0508155102.

Weeks, J. (2004). The role of spatial analysis in demographic research. In: Goodchild, M.F. and Janelle, D.G. (eds.). Spatially integrated social science. New York, NY: Oxford University Press: 381-399. 
Weeks, J. (2006). Population. Belmont, CA: Wadsworth/Thomson Learning.

Wheeler, D.C. (2007). Diagnostic tools and a remedial method for collinearity in geographically weighted regression. Environment and Planning A 39(10): 24642481. doi:10.1068/a38325.

Wheeler, D.C. (2009). Simultaneous coefficient penalization and model selection in geographically weighted regression: The geographically weighted lasso. Environment and Planning A 41(3): 722-742. doi:10.1068/a40256.

Wheeler, D.C., and Páez, A. (2010). Geographically weighted regression. In: Fischer, M.M. and Getis, A. (eds.). Handbook of applied spatial analysis: Software tools, methods and applications. Berlin: Springer: 461-486.

Wheeler, D.C. and Tiefelsdorf, M. (2005). Multicollinearity and correlation among local regression coefficients in geographically weighted regression. Journal of Geographical Systems 7(2): 161-187. doi:10.1007/s10109-005-0155-6.

Wong, D.W.S. (2002). Spatial measures of segregation and GIS. Urban Geography 23(1): 85-92. doi:10.2747/0272-3638.23.1.85.

Wong, D.W.S. (2004). Comparing traditional and spatial segregation measures: A spatial scale perspective. Urban Geography 25(1): 66-82. doi:10.2747/02723638.25.1.66.

Woods, R., and Rees, P.H. (eds.). (1986). Population structures and models: Developments in spatial demography. London, UK: G. Allen and Unwin.

Yang, T-C., Jensen, L., and Haran, M. (2011). Social capital and human mortality: Explaining the rural paradox with county-level mortality data. Rural Sociology 76(3): 347-374. doi:10.1111/j.1549-0831.2011.00055.x.

Yang, T.-C., and Matthews, S.A. (2012). Understanding the non-stationary associations between distrust of the health care system, health conditions, and self-rated health in the elderly: A geographically weighted regression approach. Health \& Place 18(3): 576-585. doi:10.1016/j.healthplace.2012.01.007.

Yang, T.-C., Teng, H.-W., and Haran, M. (2009). The impacts of social capital on infant mortality in the U.S.: A spatial investigation. Applied Spatial Analysis and Policy 2(3): 211-227. doi:10.1007/s12061-009-9025-9.

Yang, T.C., Wu, P.-C., Chen V.Y.-J., and Su H.-J. (2009). Cold surge: A sudden and spatially varying threat to health? Science of the Total Environment 407(10): 3421-3424. doi:10.1016/j.scitotenv.2008.12.044. 
Zenk, S.N., Schulz, A.J., Israel, B.A., James, S.A., Bao, S., and Wilson, M.L. (2005). Neighborhood racial composition, neighborhood poverty, and the spatial access of supermarkets in metropolitan Detroit. American Journal of Public Health 95(4): 660-667. doi:10.2105/AJPH.2004.042150.

\section{Selected Internet Resources for spatial data mapping, analysis and training resources (All links checked December 16, 2012)}

GIS and Advanced Spatial Analysis workshops

- http://csiss.ncgia.ucsb.edu/GISPopSci and http://gispopsci.org/

Future Directions in Spatial Demography

- http://ncgia.ucsb.edu/projects/spatial-demography

Teach Spatial

- http://www.teachspatial.org

The Geoda Center, Arizona State University

- http://geodacenter.asu.edu

Geospatial Analysis Online

- http://www.spatialanalysisonline.com/

Color Brewer

- http://colorbrewer2.org

R spatial tools

- http://cran.r-project.org/web/views/Spatial.html

Geostatistics website

- http://www.ai-geostats.org

Spatial Demography (a new e-journal)

- http://spatialdemography.org/ 
Matthews \& Parker: Progress in Spatial Demography 